\title{
Pinturas murales del yacimiento romano de Cambre (A Coruña)
}

Mural paintings of the Roman site of Cambre (A Coruña)

\author{
María Loira Enríquez \\ Departamento de Prehistoria y Arqueología \\ Universidad Nacional de Educación a Distancia-UNED \\ mariettale@hotmail.com
}

\section{Resumen}

Nuestro propósito es presentar las pinturas murales de la zona arqueológica de Cambre (A Coruña), en el NW de Hispania. Se trata de un paisaje marino que decora la bóveda de un frigidarium e imitaciones marmóreas en las paredes. Pertenecen a una villa romana que estaba activo en el siglo cuarto. Estas pinturas se ponen en contexto y se comparan sus similitudes.

\section{Palabras clave}

Pinturas romanas, villa, Gallaecia, balneum, frigidarium, paisaje marino, crustae, Antigüedad Tardía.

\begin{abstract}
Our purpose is to present the wall paintings of the archaeological site of Cambre (A Coruña), in the north west of Hispania. It deals with a seascape that decorates the vault of a frigidarium and marmoreal imitations on the walls. They belong to a Roman villa that was active in the 4th century. These paintings are described, put into context as well as compared for similarities.
\end{abstract}

\section{Key words}

Roman paintings, villa, Gallaecia, balneum, frigidarium, seascape, crustae, late Antique. 


\section{Contexto ARqueológico}

Los fragmentos de pintura mural que presentamos a continuación ${ }^{1}$ se descubrieron en el yacimiento arqueológico de Cambre (A Coruña). (Fig. 1).

En el año 1998 la construcción de un bloque de edificios frente a la iglesia de Santa María $^{2}$ lleva consigo la aparición de materiales y estructuras que evidencian una presencia romana y la consecuente intervención arqueológica que se hará bajo la dirección del arqueólogo D. Juan Naveiro López.

Desde antiguo se había advertido la existencia de un yacimiento romano, pues aparecían restos en superficie en el área de dicha iglesia, que formó parte de un monasterio del siglo X (CASTILLO 1987: 89).

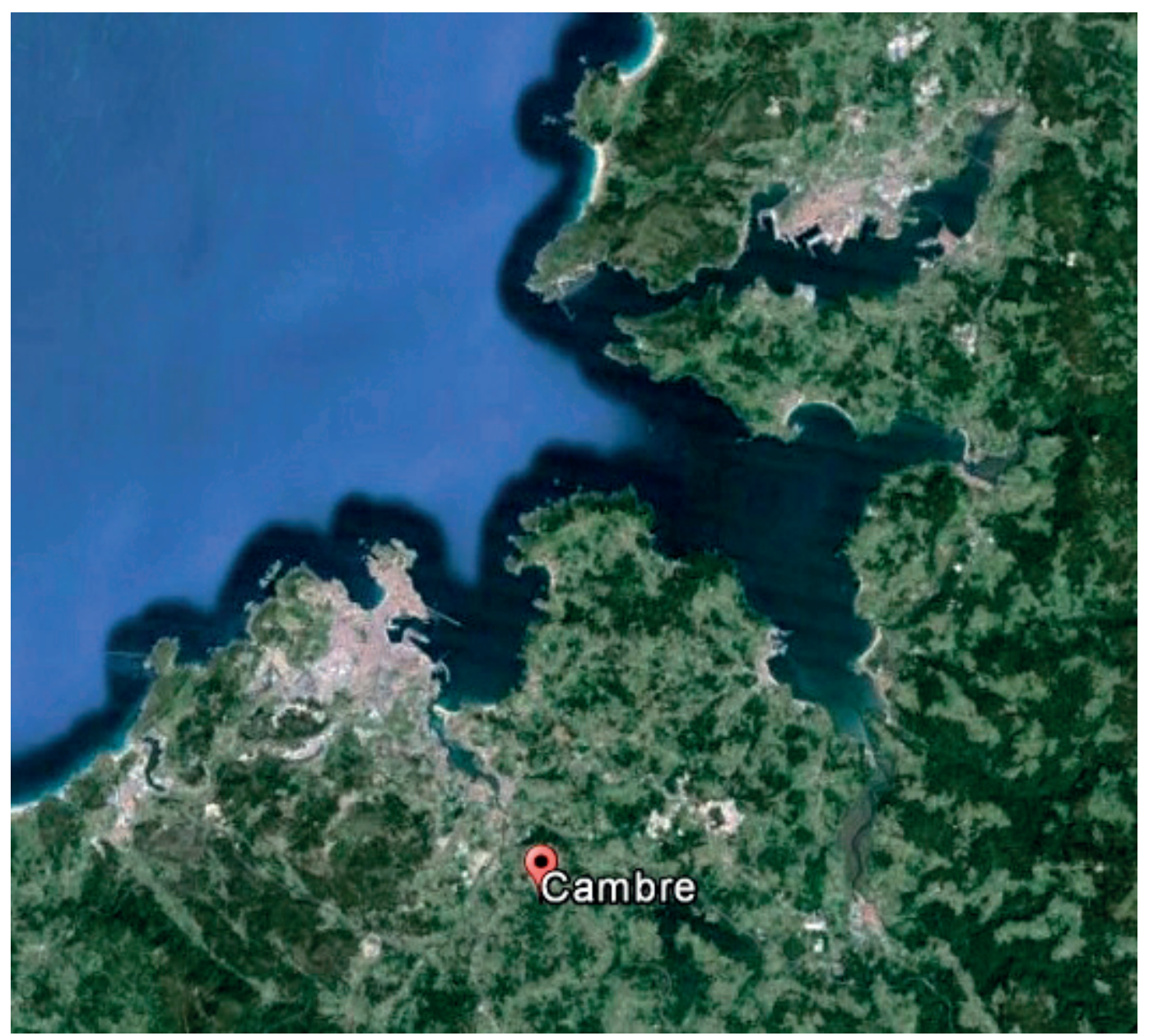

Figura 1. Situación de Cambre en el Golfo Ártabro.

1 El presente artículo parte de un trabajo elaborado en el Curso de Docencia de Pintura romana en España correspondiente al programa de Doctorado en Arquelogía romana de la UNED e impartido por la profesora Carmen Guiral a quien agradecemos, además de su enseñanza, las aportaciones a este estudio.

2 La iglesia románica de Santa María de Cambre, catalogada desde 1931 como Bien de Interés Cultural, incluye estos terrenos en su ámbito de protección. 
Unos años antes de llevar a cabo la excavación, durante la edificación de otro bloque de viviendas, se encontró abundante material romano de construcción y afloraron estructuras pero no hubo intervención arqueológica en ese momento y se perdió información. Los trabajos se llevaron a cabo, de manera intermitente, desde la primavera al otoño del año 1998 de acuerdo con la aparición de materiales.

Tras la intervención de urgencia las estructuras recuperadas fueron trasladadas y hoy están expuestas en el Centro de Interpretación a unos $50 \mathrm{~m}$. de su ubicación original, junto con algunos materiales y los fragmentos pictóricos recuperados. Los vestigios se identificaron como pertenecientes a una villa tardorromana ${ }^{3}$ (NAVEIRO LÓPEZ et al. 2008: 21).

Los restos arquitectónicos puestos al descubierto corresponden a un balneum, en concreto frigidarium y latrinae, perteneciente a una villa romana del siglo IV d.C. Ambas estructuras forman una construcción de doble cuerpo separadas por un muro de mampostería (Fig. 2), anexo a ellas un patio abierto que podría tratarse de una palestra y una piscina o natatio (NAVIERO LÓPEZ et al. 2008: 18).

El frigidarium es un espacio abovedado y de planta rectangular con una pileta cuadrangular de opus signinum de gran calidad, pintada de blanco y con los esquinales reforzados para impermeabilizar los bordes. A la piscina se accede por tres escalones revestidos con el mismo opus signinum; actualmente presenta una tonalidad anaranjada pero antes del traslado tenía un color más rojizo. Se trata de un tipo de mortero hidráulico de cal, arena de gránulo medio y fragmentos de ladrillo en el que se distinguen dos capas de aplicación (NAVEIRO LÓPEZ et al. 2008: 31). Esta estructura, junto con las latrinae adyacentes, ocupa una superficie de $7^{\prime} 38 \mathrm{~m}$. x 4'16 m.

Los hallazgos de pinturas se circunscriben a la zona del frigidarium. Los restos decorativos permiten concluir que la bóveda estaba pintada con motivos de fauna marina de gran naturalismo sobre un fondo gris azulado y las paredes con imitaciones marmóreas, cenefas y un motivo arquitectónico (Fig. 3).

En el año 2012, de manera casual, aparecieron almacenados un nuevo grupo de fragmentos lo que aumenta significativamente la superficie decorada constatada con anterioridad 4 .

3 Juan Naveiro López, director de la excavación, ha considerado también la hipótesis de que se tratase de una mansio, por su situación cercana al camino natural que uniría Flavium Brigantium con Lucus Agusti y por la sobredimensión de su área termal (NAVEIRO LÓPEZ et al. 2008: 25). Por su parte, Fermín Pérez Losada abre la posibilidad de que se tratase de un aǵlomerado termal menor con termas públicas o bien privadas de uso público, considerando que balneum, latrinae y patio o palaestra frontal abierta exceden el ámbito doméstico (PÉREZ LOSADA 2002: 322). Consideramos que ninguna de las características señaladas invalida el hecho de que estemos ante un establecimiento tipo villa puesto que la cercanía a una vía es una indicación de los agrónomos latinos para ubicarlas (FERNÁNDEZ CASTRO 1982: 49) y en lo que se refiere a dimensiones del balneum no son extraordinarias en una villa tardorromana si se establecen paralelos con otras villae hispanas de igual cronología. Por otro lado, los dos hipocaustos posibles (GONZÁLEZ SOUTELO 2011: 191-192) no necesariamente habrían de estar relacionados con una zona termal, al menos uno podría servir para calefacción en seco; incluso de pertenecer ambos a un área termal podría deberse a una reestructuración de estos espacios, ya que desde época bajoimperial los balnea sufren un proceso de monumentalización notable (GARCÍA ENTERO y ARRIBAS DOMINGUEZ 2000: 92).

4 Se trata de decenas de piezas de diferente tamaño que están a la espera de una decisión de la Dirección Xeral de Patrimonio de la Consellería de Cultura de la Xunta de Galicia sobre la actuación a seguir. Por deferencia de Ramón Boga, responsable del Centro de Interpretación del yacimiento romano de Cambre, al que agradecemos la información y las facilidades para desarrollar nuestro trabajo, hemos tenido acceso a los nuevos fragmentos pictóricos recuperados. Esto nos ha permitido algunas matizaciones y consideraciones con respecto a las conclusiones primeras sobre estas pinturas. 


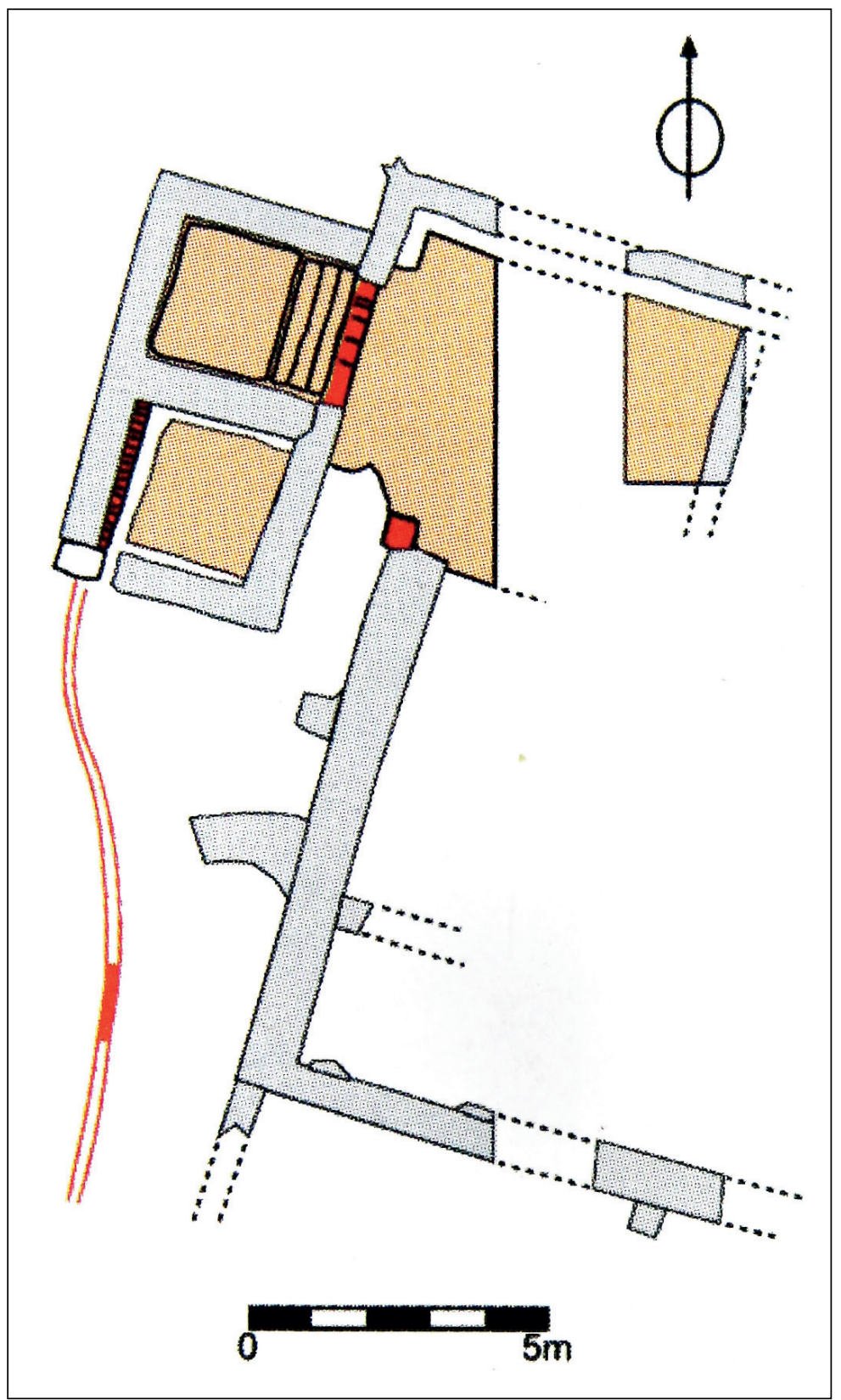

Figura 2. Balneum de Cambre (GONZÁLEZ SOUTELO 2011: 198).

\section{Descripción de LAS PINTURAS}

Nuestro objeto de estudio se centra en los 70 fragmentos recuperados inicialmente y musealizados en el Centro de Interpretación del yacimiento arqueológico de Cambre, que permiten conocer parte de la decoración pictórica del frigidarium. Aunque la superficie conservada es muy pequeña, la representatividad de los restos es suficiente para poder abordar su estudio e interpretación.

\section{Motivos marinos}

Motivo marino a) (Fig. 4): un gran pez dividido en doce fragmentos de muy diferente tamaño; las medidas van desde los $26 \mathrm{~cm}$. x $11 \mathrm{~cm}$. a los $3,5 \mathrm{~cm}$. x $2 \mathrm{~cm}$. En algunas partes 
se distingue el fondo marino en tono gris azulado. El color del pez es rojo en diferentes tonalidades, aletas y branquias en rojo más oscuro, tono que se utiliza también para las líneas longitudinales que le dan volumen. Presenta una gran minuciosidad en los detalles -ojo, aleta caudal, ventral y branquias-.

La clasificación ictiológica ${ }^{5}$ no es fácil en ninguna de las especies representadas. En este caso podría tratarse de un escómbrido -atún o similar-, a juzgar por los trazos de la cabeza, pero el color resulta ficticio ya que estos peces son azules grisáceos o verdosos. Por el perfil podría tratarse de un espárido, por ejemplo una dorada (sparus aurata), de aguas litorales y muy apreciada en la gastronomía romana. Estamos ante una libre interpretación, aunque todas las características remiten a un tipo de pez óseo marino. Presenta similitud con la especie recogida en el mosaico del Seminario de Santiago en Braga (ACUÑA CASTROVIEJO 1974: fig 6).

Motivo marino b) (Fig. 4): en un fragmento de $25 \mathrm{~cm}$. x $18 \mathrm{~cm}$. se vislumbran sobre el fondo marino unos contornos que se han interpretado como peces. El de la parte inferior podría ser del mismo tipo que el motivo a) (Fig. 4), ya que la aleta caudal es similar y también el color. Como en el caso anterior, nada en dirección izquierda y una línea amarilla dibuja el contorno. El de la parte superior es de tonalidades amarillas, verdosas y blancuzcas; sus formas son más imprecisas y desdibujadas. Tenemos dudas de que se trate verdaderamente de un pez, ya que el resto presenta minuciosos detalles; consideramos la posibilidad de que se trate de una almeja ciprea o bien una tapes decussatus, un motivo frecuentemente representado en los mosaicos marinos del noroeste y constatado en Panxón, Parada de Outeiro, Braga, Lugo y León (ACUÑA CASTROVIEJO 2013: 150).

Motivo marino c) (Fig. 4): fragmento de 13,5 cm. x $8 \mathrm{~cm}$. que representa una morena común (muraena helena) de color amarillento, más claro en la parte inferior y con una especie de circunferencias en tonos rojizos que le proporciona el aspecto de piel de serpiente. El contorno del pez lo bordea una raya blanca. La morena fue una especie muy apreciada en la gastronomía romana y muy representada en su arte. En dos ocasiones se aprecia este motivo en los mosaicos de temática marina de Gallaecia, en Braga y en Lugo (ACUÑA CASTROVIEJO 2013: 150).

Motivo marino d) (Fig. 4): un pequeño fragmento de $9 \mathrm{~cm}$. x $4 \mathrm{~cm}$. que representa el abdomen de algún tipo de ciprínido o carpa (cyprinus carpio) por la forma tan peculiar de dibujar las escamas -a base de rombos en una tonalidad más oscura y con una pincelada que deja una mancha en medio-. Las líneas que marcan las escamas sobrepasan el vientre del pez y continúan sobre el agua, lo que denota un cierto descuido en la ejecución y que el motivo está superpuesto a la tonalidad grisácea del mar. También en esta ocasión una línea amarilla delimita la figura del pez.

Motivo marino e) (Fig. 4): un pulpo del que se conservan once fragmentos de muy diferentes dimensiones - de $2 \mathrm{~cm}$. x $1 \mathrm{~cm}$. a $13 \mathrm{~cm}$. x $11 \mathrm{~cm}$.-, representan la cabeza con

5 Para la clasificación ictiológica de las especies representadas hemos considerado la opinión de Antonio Pérez Cribeiro, Jefe de Biología Marina del Acuarium Finisterre de A Coruña, a quien agradecemos toda la información aportada. 
ojos y tentáculos con ventosas rojizas. El pulpo (octopus vulgaris) es de color amarillo verdoso y está dibujado con gran verismo y sensación de movimiento. En el noroeste, es un motivo también recogido en mosaicos de Braga, Canelas y Villaquejida (ACUÑA CASTROVIEJO 2013: 150).

Motivo marino f) (Fig. 4): en los fragmentos central e izquierdo, 11,5 cm. x 8 cm. y 14 cm. x 8,5 cm. respectivamente, aparece pintada una vieira. En el primero se plasman con gran detalle las ondulaciones de la concha del bivalvo en tonos ocres, grises, verdosos y blancos.

Motivo marino f) (Fig. 4): aunque en la musealización se recoge como un único motivo, consideramos que, en la parte derecha, se observa una caracola en diferentes tonalidades ocres -en un fragmento de $10 \mathrm{~cm}$. x $14 \mathrm{~cm}$.- y en un lateral, se inicia un nuevo motivo del que sólo se percibe una leve línea ocre, lo que hace imposible cualquier interpretación.

La fauna representada en las pinturas de Cambre es propia de aguas atlánticas, con excepción de los ciprínidos, que sí se pueden encontrar en los ríos galaicos. De ello se puede inferir que reflejan un mundo marino conocido y reconocible: vieiras (pectinidae), pulpos (octopode) y almejas (tapes), especies características de las rías gallegas; los escombridos y espáridos del Mediterráneo no son extraños al ámbito atlántico; aunque son más abundante en las cálidas aguas mediterráneas todavía pueden encontrarse hoy día algunos ejemplares de morena (muraena helena) en las costas gallegas. En este sentido, cabe suponer variaciones en la fauna marina en un momento que disfrutó de una bonanza climática (MARTÍNEZ CORTIZAS y VÁZQUEZ VARELA 2002: 93).

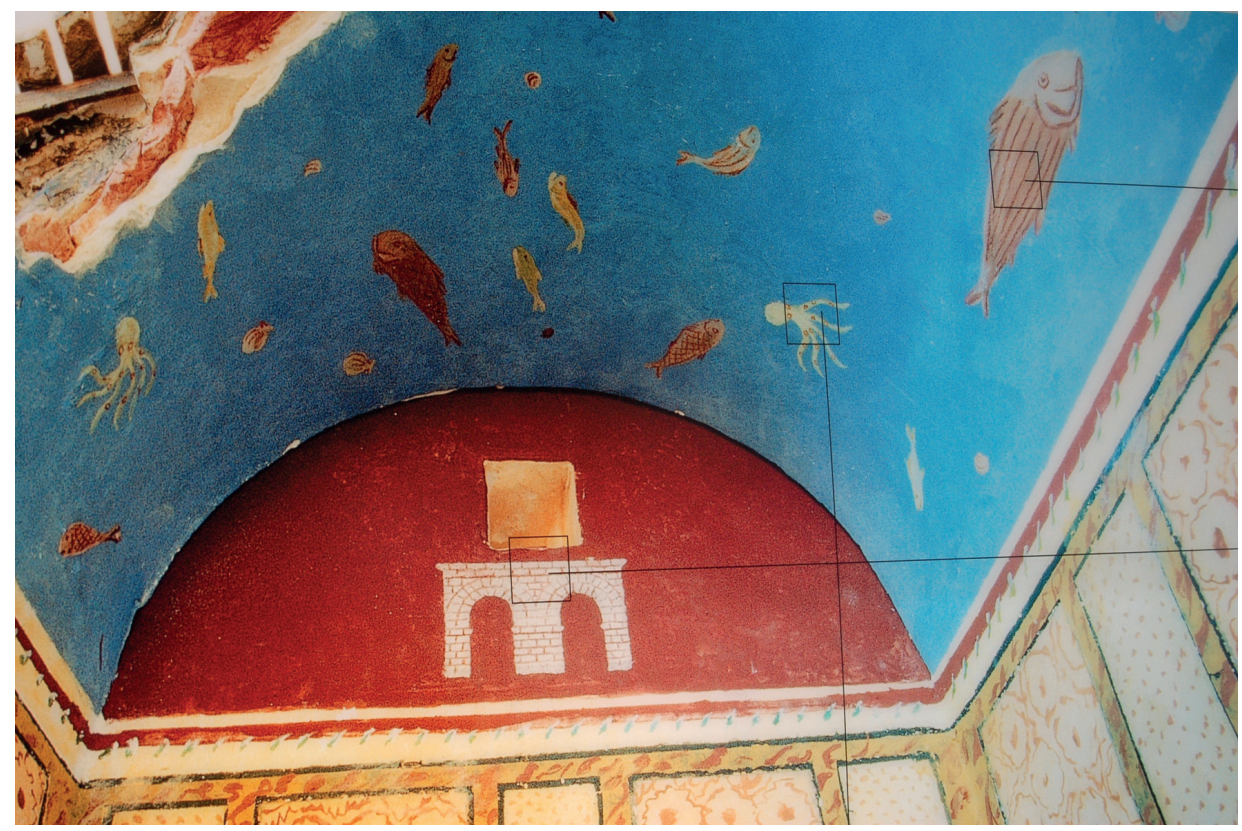

Figura 3. Reconstrucción hipotética de la bóveda (Exposición del Centro de Interpretación del yacimiento romano de Cambre).

6 Tampoco se observa movimiento del agua en los fragmentos de similar temática y cronología de la villa de Requejo conservados en el Museo de Zamora. Y sí en los pertenecientes a las termas junto a la Casa de Mitreo de Mérida, en donde el movimiento del agua se representa con trazos en blanco en E y F (ABAD CASAL 1982 a: 371). 
El agua aparece en muchos de los fragmentos como fondo; la tonalidad que presenta es grisácea. El movimiento de las aguas, que es una constante en los mosaicos de tema marino, se representa de modo similar en todos ellos en el noroeste. Esta representación del movimiento también es habitual en la pintura romana (ABAD CASAL 1982 a: 373). Sin embargo, no se percibe ningún signo indicador del movimiento en estos fragmentos ${ }^{6}$.

\section{Imitaciones marmóreas}

Las imitaciones marmóreas decoran parte de las paredes del frigidarium.

Crusta a) (Fig. 5): placa con imitación de mármol brocatel de fondo ocre y vetas rojizas; este motivo está separado por un filete negro de un panel en rojo. Se conservan ocho pequeños fragmentos de medidas entre $2,5 \mathrm{~cm}$. x $2 \mathrm{~cm}$. y $5 \mathrm{~cm}$. x 5,6 cm.

Crusta b (Fig. 5): se trata de una imitación de mármol veteado sobre fondo rosáceo. Los veteados están hechos en diferentes tonos de rojizos que parecen conseguidos aclarando las tonalidades del rojo y enmarcados por triples filetes en blanco, negro y blanco, sucesivamente. Son seis fragmentos de medidas que oscilan 2,5 cm. x $3 \mathrm{~cm}$. y 9,5 cm. x $11 \mathrm{~cm}$.

Crusta c) (Fig. 5): sobre un fondo blanquecino se dibujan pinceladas rojizas desiguales; el motivo está enmarcado por un filete amarillo y podría tratarse de un tipo de imitación marmórea. Aparece fragmentado en ocho piezas de $1,75 \mathrm{~cm}$. x 2,5 cm. a 5,3 cm. x a $3,5 \mathrm{~cm}$.

\section{Cenefa}

Se recuperaron tres fragmentos de entre $3 \mathrm{~cm}$. x $3 \mathrm{~cm}$. y 4,5 cm. x 4,5 cm. El motivo presenta una línea roja con círculos del mismo color adosados en un lateral, todo sobre fondo blanquecino; debajo de los pequeños círculos aparecen otros menores que no son más que simples puntos en el mismo tono rojo.

\section{Motivo arquitectónico}

Representa una doble arcada que apareció fragmentada en 17 piezas de medidas entre $11 \mathrm{~cm}$. x $9 \mathrm{~cm}$. y $1 \mathrm{~cm}$. Este último fragmento, aunque muy pequeño, es muy definitorio porque marca la línea del arco (Fig. 5). El motivo, que dibuja una arquería de sillares regulares pintados en rojo sobre fondo blanquecino-amarillento, ha sido interpretado como una doble puerta como representación simbólica de la ciudad (NAVEIRO LÓPEZ et al. 2008: 17). 


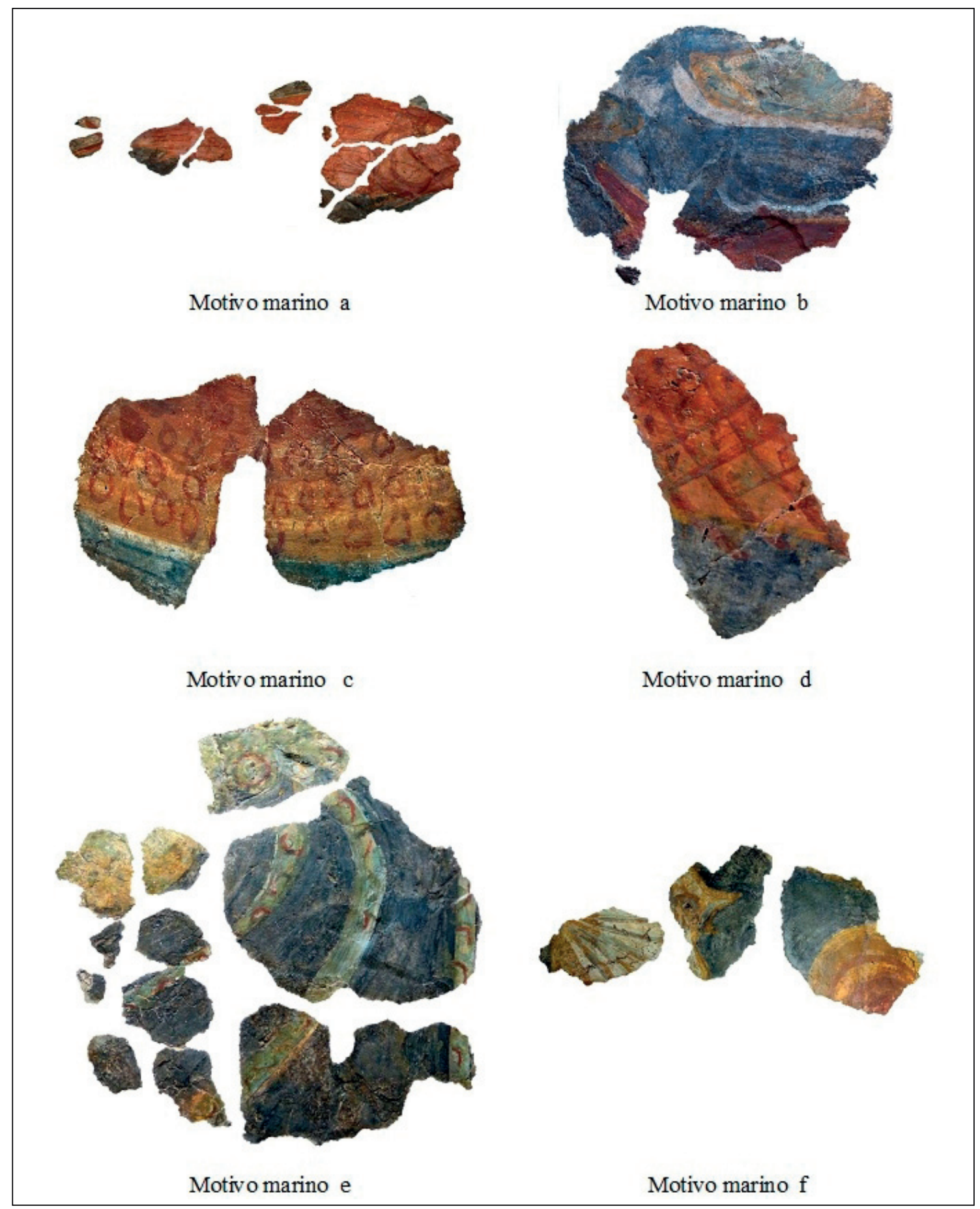

Figura 4. Motivos marinos.

\section{RESTITUCIÓN HIPOTÉTICA}

A partir de estos restos arqueológicos, consideramos una restitución hipotética con las oportunas reservas dado el estado de conservación de las pinturas. Planteamos exclusivamente la secuencia decorativa ya que no existen datos que permitan conocer las medidas aproximadas de las superficies. 
De arriba abajo el espacio se divide del modo siguiente: una bóveda decorada con un paisaje marino de gran naturalismo, que se reflejaría en la piscina de fondo blanco con objeto de dar al ambiente la sensación de hallarse en un medio natural, una solución muy común en los frigidaria (GUIRAL PELEGRÍN, 2000 a: 115). El color predominante de la bóveda sería el azul del agua o bien el rojizo. Nos inclinamos por esta segunda opción a tenor de la superficie total de pintura recuperada en la que aparece este color. Es el pigmento de la mayor parte de los peces y recuerda la decoración del frigidarium de la Villa de Requejo con gran profusión de fauna marina (REGUERAS GRANDE, 1992: 115). De ser así, proporcionaría un ambiente más bien oscuro, una costumbre que venía de antiguo, ex consuetudine antiqua, como advertía Séneca (Ep.86.4). Este tipo de decoración no era ya novedoso en el momento de existencia de la villa en los siglos IV-V d.C., pues su momento de auge estuvo entre la segunda mitad del II d.C. y principios del III d.C. (ABAD CASAL, 1982 a: 373).

La pertenencia a la bóveda de los motivos marinos está justificada por la ligera concavidad que presentan los fragmentos recuperados.

La decoración parietal está dividida en diferentes bandas. La inicia, desde arriba, un friso compuesto por una arquería ${ }^{7}$ que remite a un puente o a alguna estructura en relación con las aguas que dominan la bóveda y la piscina.

A continuación la parte media, que muy probablemente se haya perdido. La bóveda se habría venido abajo sobre la piscina sellando la parte inferior correspondiente a las zonas más bajas, de ahí que lo conservado sean las crustae de los zócalos. En ocasiones este tipo de imitaciones marmóreas adornan las partes altas de las paredes, tal y como sucede en la Casa de Mitreo en Mérida (ABAD CASAL, 1982 a: 64-67), aunque es más frecuente encontrarlas en zonas bajas. Las crustae aparecen en la zona media en época republicana (I y II estilos); posteriormente, en el siglo I d.C. (III y IV estilos), se reducen a los zócalos y desde mediados del II d.C. hasta el IV d.C. vuelven a aparecer en la zona media de la pared. No obstante, también son frecuentes los ejemplos que decoran exclusivamente el zócalo.

En ocasiones las crustae hacen de división entre motivos. Con las evidencias de las que disponemos, no podemos deducir una clara adscripción a un lugar concreto.

Por último, las cenefas estarían marcando la división entre las diferentes bandas horizontales. Se conserva la del motivo de gotas de agua, quizá separando el zócalo de la parte media.

\section{Técnicas de EJeCUCión de las PINTURas}

La falta de análisis en pigmentos y morteros impide un estudio en profundidad que ampliaría el conocimiento de las pinturas y del propio establecimiento. Conocer el grosor de

7 La solución proponía anteriormente planteaba una puerta con significado simbólico en relación con la ciudad (NAVEIRO LÓPEZ et al. 2008: 17), esto hay que reconsiderarlo ya que entre los hallazgoos recientes han aparecido más fraǵmentos con idéntico motivo, lo que estaría indicando una continuidad en las arquerías. 
los morteros permitiría una mayor seguridad a la hora de abordar la restitución hipotética ya que son más gruesos en los zócalos y se afinan a medida que ascienden en la pared.

Tampoco existe información sobre los sistemas de sujeción utilizados para conseguir la adherencia al muro, que ayudarían a determinar la disposición de las pinturas del anverso. Como estas sujeciones suelen presentarse en dirección perpendicular al suelo de las habitaciones permitirían avanzar en el resultado final del sistema decorativo.

Los trazos preparatorios, que se efectuaban sobre el enlucido húmedo con el fin de que el esquema compositivo quedase marcado en las paredes, no son siempre perceptibles a simple vista. En las pinturas de Cambre se observan en forma de incisiones en los rectángulos que perfilan las crustae, (Fig. 5 crustae b), en vertical en la línea negra y en horizontal en la última línea blanca. Este tipo de trazo preparatorio es el más común en todo el Imperio (ABAD CASAL 1982 b: 147). No parece haber trazos preparatorios en la ejecución de los sillares del motivo arquitectónico (Fig. 5 motivo e), ya que las líneas son vacilantes y no mantienen una recta firme.

En cuanto a pigmentos, no se conoce el grosor de la película, ni si hay superposición de colores o existencia de posibles repintes al no haberse efectuado análisis al microscopio; también se desconoce su composición mineralógica, sólo definible a partir de análisis químicos, difracción electrónica, termoanálisis diferencial o fluorescencia de Rayos $\mathrm{X}$; falta además información sobre la homogeneidad o no del pigmento que habría de analizarse con lupa binocular. Estos datos ampliarían el conocimiento sobre la calidad técnica y artística que hablaría, a su vez, de la riqueza del edificio.

La calidad de los pigmentos en la pintura romana es muy variada. Algunos son verdaderamente costosos; entre estos estarían el minium, el azul de Armenia, el purpureum, el chrysocolla o el ostrum (ABAD CASAL 1982c: 398), son los denominados floridi por Plinio, pero estos colores también se podían obtener a partir de materias que abaratasen el producto, imitando los caros. Se desconocen las fórmulas empleadas en los pigmentos de Cambre. A esto hay que añadir que, en ocasiones, los pigmentos están alterados al haber estado en condiciones difíciles -expuestos a un exceso de humedad, al aire libre o por haber sufrido una deshidratación tras un incendio- o bien alterados intencionadamente con el ánimo de abaratar costes, por ejemplo aplicando determinados colores sobre pigmentos caros para realzar su colorido (ABAD CASAL 1982c: 398 y ss.), también aplicando una capa de azul grisáceo bajo el azul de la superficie economizando así el pigmento, tal y como se detectó en las termas de Bilbilis (GUIRAL PELEGRÍN 1994: 49).

En el balneum de Cambre la representación del mar es de un tono grisáceo, pero con la información disponible no se puede afirmar taxativamente que se deba a la circunstancia mencionada. Efectivamente el azul es un producto caro y su empleo es limitado. En Hispania sólo se ha constatado en grandes superficies en el caso de las termas de Bilbilis (GUIRAL PELEGRÍN 2000 b: 24 y 29).Vitrubio (VII, 11) explica la compleja elaboración del caeruleum aegyptium a partir de arena y sal mineral amasadas con bronce de Chipre, pero también se pueden conseguir otras variedades de caeruleum a más bajo coste, por ejemplo el scythicum, ciprium o el hispalense (ABAD CASAL 1982 c: 402).

En las pinturas analizadas abundan los diferentes matices de rojo que mantienen bien el color. Ateniéndonos a los fragmentos recuperados en la musealización es el color 
predominante en la bóveda, ya que es el color de la mayor parte de los peces, dispuestos con cierto abigarramiento; oscila de los tonos rosáceos a los rojos profundos. También forma parte de la cenefa, de las imitaciones marmóreas parietales y dibujando sillares y dovelas de la arquería. Estas tonalidades podrían tener distinto origen o ser variaciones de un mismo pigmento. Es verdad que el rojo puede ser un pigmento muy caro, como lo es el rojo cinabrio, pero existieron falsificaciones en las que se usó óxido de plomo, el llamado minium secundarium en lugar de sulfuro de mercurio (ABAD CASAL 1982c: 403). El ocre rojo es un color que se utilizó de modo habitual y podría ser el usado en Cambre.

La paleta se completa con la gama de ocres, además de negro, blanco, gris y verde.

El negro se emplea como fondo sobre el que se plasman las crustae. Las fuentes clásicas hablan de pigmentos artificiales a partir de quemados pero también los hubo naturales de origen vegetal (ABAD CASAL $1982 \mathrm{c}$ : 402).

El blanco aparece en el fondo de la cenefa (Fig. 5 cenefa d) y en el motivo decorativo (Fig. 5 motivo decorativo c). Se utiliza, además, para marcar unas líneas de sombreado en los tentáculos del pulpo (Fig. 4 motivo e). Con toda probabilidad se habrá mezclado con el negro para elaborar los grises. Puede haberse obtenido de sustancias calcáreas, dando como resultado el cretae o de mezclar plomo con vinagre, el llamado blanco de plomo o cerussa (ABAD CASAL 1982 c: 402) aunque lo más habitual es el blanco de cal.

El verde también puede tener distinta procedencia y de ahí un diferente coste, desde el más preciado chrysocolla a verdes más económicos como el aeruga o el creta viridis (ABAD CASAL 1982 c: 403). Aparentemente en Cambre no es un color predominante, ya que sólo está presente en las irisaciones de la vieira y en el pulpo. La tonalidad grisácea que presenta actualmente el agua podría deberse a un verde de malaquita degradado con el paso del tiempo al ser aplicado al fresco, ya que para que mantuviese el color tendría que ser aplicado sobre el arriccio seco. Esto hablaría también de la técnica empleada en la ejecución, pero no existen pruebas fehacientes al respecto y, por otra parte, los verdes de malaquita son muy extraños en la pintura romana.

Abundan los ocres en las crustae. También se utiliza para dibujar los contornos de los peces y se observa en la vieira, la caracola y la almeja. Probablemente se trate de pigmentos conseguidos a partir de óxidos de hierro (ABAD CASAL 1982 c: 399).

En relación con las técnicas pictóricas empleadas, advertir que tradicionalmente se ha aplicado la denominación de "fresco" a cualquier pintura mural, aunque hubiese sido realizada con otra técnica. Discernir cuál no es siempre fácil, aún después de análisis de laboratorio. En teoría la identificación del fresco sería fácil si se percibiesen las uniones de las diferentes jornadas de trabajo. Pero esto no se cumple casi nunca en las pinturas romanas, ya que el enlucido tenía unas características que le hacía conservarse húmedo más tiempo y podía ser pintado en un espacio de tiempo mayor y también en superficies más extensas, a diferencia de lo que ocurre, por ejemplo, en el Renacimento (ABAD CASAL 1982 b: 154).

El fresco consiste en la aplicación sobre el enlucido húmedo de colores disueltos en agua. El proceso químico que se produce a continuación al reaccionar el anhídrido carbónico del aire con la cal del enlucido permite que el color se conserve. Los autores clásicos distinguen entre colores que pueden ser aplicados al fresco y otros que necesitan el enlu- 
cido seco. Plinio (XXXV) afirma que colores como el purpurissum, el indicum, el caeruleum, el melium, el auripigmentum, el appianum y el cerussa no podían ser aplicados sobre el enlucido húmedo, por tanto, técnicamente no podrían utilizarse para pinturas “al fresco". En todo caso, conocer la técnica empleada presenta problemas y no se puede afirmar sin análisis específicos que se trate exclusivamente de fresco; es muy probable que se haya utilizado la variante $a \operatorname{secco}^{8}$ para los detalles. También pudo haberse utilizado temple ${ }^{9}$ para algunos motivos ya que se observa mayor densidad de pigmento en algunas partes, especialmente en pinceladas sobre los peces.

Las distintas calidades en la ejecución de estas pinturas indican diferentes operarios, quizá también diferentes momentos. En general, los motivos marinos de la bóveda presentan una técnica más depurada que la decoración de las paredes.

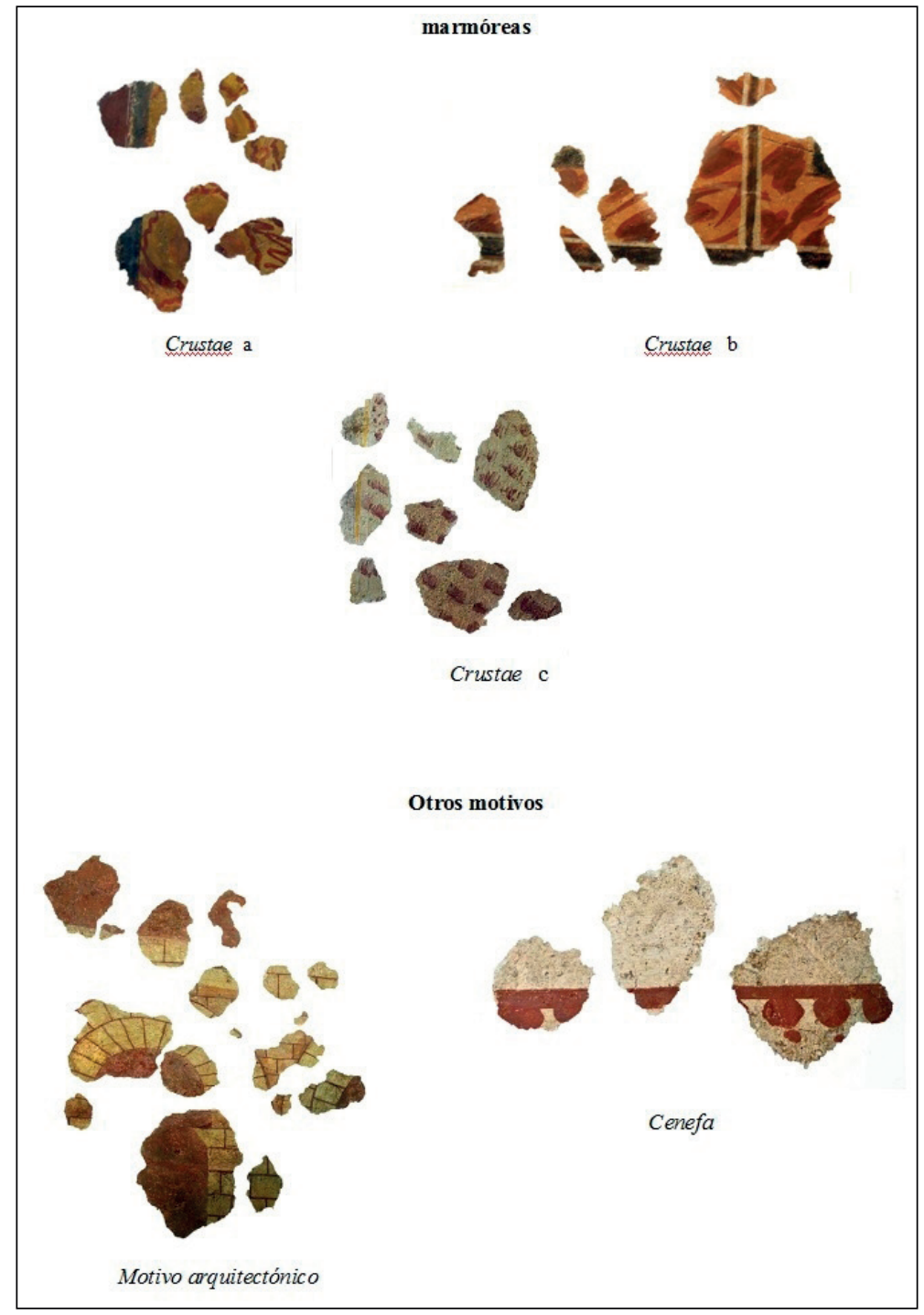

Figura 5. Imitaciones marmóreas y otros motivos.

8 La técnica a secco es una variedad de la técnica del fresco, ya que los colores son aplicados disueltos en aơua de cal sobre el enlucido seco, de ahí el nombre. Normalmente se utiliza para los detalles.

9 En la técnica del temple se utiliza un aglutinante que puede ser huevo, cola, goma arábiga, aceite, caseína, etc. aunque identificarlo tiene su dificultad aún a través de análisis químicos debido a que los aglutinantes pueden transformarse o desaparecer (ABAD CASAL 1982b: 153). 


\section{Paralelos, datación e interpretación}

Las pinturas murales de Cambre presentan unos esquemas decorativos que se repiten a lo largo del tiempo y en múltiples espacios del mundo romano. A la hora de establecer paralelos han de diferenciarse los cuatros tipos decorativos: el paisaje marino, las imitaciones marmóreas, el motivo arquitectónico y la cenefa.

Ya hemos incidido en la idea de que en la pintura romana existe armonía entre la temática y los espacios a decorar. En este sentido, el paisaje marino es propio y habitual de los frigidaria, aunque no exclusivo, y suele ocupar las bóvedas (GUIRAL PELEGRÍN 2000 a: 115). Existen múltiples ejemplos en relación con esto, el más antiguo del que se tiene constancia es el de las Termas de Herculano, del siglo I a.C., en el que sobre fondo azul celeste se disponen peces de distinto tamaño sin orden especial (ABAD CASAL, 1982 a: 372-373). El tema se sigue representando a lo largo de todo el periodo hasta el final del momento romano. De mediados del siglo II d. C. es el balneum de la villa de Schwangau en Tegelberg (Alemania) en donde especies marinas cubren la bóveda y una ventana en trampantojo ocupa la pared del fondo ${ }^{10}$.

La mayoría de las bóvedas conservadas con decoraciones de peces son de la segunda mitad del siglo II d.C. y principios del III d.C., que es el momento de auge de estos motivos en pintura (ABAD CASAL 1982 a: 373). Justamente a esta época corresponde la decoración de las estancias termales del sureste de la Casa de Mitreo en Mérida (ABAD CASAL 1982 a: 65). El frigidarium de Ca l'Alemany, en Badalona, es de un momento indeterminado entre el siglo II d.C. y III d.C. (GARCÍA ENTERO 2005-2006: 64-65, nota 15), aquí sobre fondo azulado se representan diferentes especies entre las que destacan los delfines y una especie de langosta o caballo de mar (GARCÍA ENTERO 2005: 847). De nuevo lo encontramos en Lisieux y en Lyon, concretamente en Clos de la Solitude en las termas de la Rue de les Farges, con conchas de difícil identificación (BARBET 2008: fig. 474), éstas también del siglo II. En Langon, en la capilla de Sainte Agathe, el ábside se pinta con la imagen de Venus y Amor, éste último sobre un delfín, alrededor un paisaje marino (BARBET 2008: fig. 477). Así mismo, el tema ictiográfico aparece en las villas suizas de Münsingen (KAPOSSY 1966: 16) y Holstein, donde bóveda y pared están decoradas con peces de diversos colores, delfines y moluscos (KAPOSSY 1966: 33-34 y 43). Ambas villae se encuadran cronológicamente en el época de los Severos (DRACK 1988: 57-59), entre el 190 d.C. y el 250 d.C.. Un ejemplo cercano lo tenemos en Asturica Augusta cuyas termas mayores fueron decoradas con un tema íctico en fechas no posteriores al III d. C (REGUERAS GRANDE 1992: 121), y en la piscina de la villa oscense de Fortunatus (ABAD CASAL, 1982 a: 371) de los siglos III y IV d.C. (RIPOLL y ARCE 2001: 28). Por último, el frigidarium de la villa de Requejo en Santa Cristina de la Polvorosa, Zamora (REGUERAS GRANDE 1992: 121), de finales del siglo IV principios del V, coincidente con la cronología de Cambre (NAVEIRO LÓPEZ et al. 2008: 20); ambos presentan similitudes aunque la factura de los peces y el colorido de éstos es diferente, como difiere también la forma de la piscina y su suelo de mosaico (REGUERAS GRANDE, 1992: fig. 1 y fig. 2).

10 http://www.schwangau.de/die-roemervilla-am-tegelber-454.html. (última visita 9-3-12) 
Los paisajes marinos decoraron también lo que Barbet denomina "bassin présumés", unas estructuras que se interpretaron como viveros o estanques, aunque parecen más bien esto último, y que lucen en sus paredes motivos de fauna marina pintados. Apenas se conocen unos pocos ejemplos en Lyon, Limoge y Vieux (BARBET 2008: fig. 475), y el más significativo que procede de la casa de la Rue des Bouquets en Perigueux que ornamenta el centro del peristilo (BARBET, 2008: figs. 469 y 470).

Un largo espacio de tiempo desde el I a.C. hasta el V d.C. en el que los gustos por este tipo de decoración marina se mantienen vigentes.

Las pinturas de Cambre son posteriores al menos en un siglo a las emeritenses. No obstante, presentan una gran similitud: en ambos casos hay un abigarramiento de especies marinas -en Mérida, los peces incluso se juntan y se superponen-y un predominio del color oscuro. El agua presenta diferencias, en Cambre el tono que llega a día de hoy es azul grisáceo mientras que el emeritense es verdoso. En las termas junto a la Casa de Mitreo se indica el movimiento del agua con los signos E y F (ABAD CASAL, 1982 a: 374), movimiento que no se observa en Cambre, al contrario de lo que sucede en los mosaicos galaicos de tema marino (BALIL ILLANA 1975: 261).

En Galicia no se han documentado otros ejemplos similares en pintura, sin embargo los motivos marinos son frecuentes en mosaicos (ACUÑA CASTROVIEJO 2013). A ellos nos hemos referido con anterioridad al establecer similitudes entre los motivos característicos que presentan estos mosaicos y la decoración de Cambre.

Las imitaciones marmóreas en la decoración pictórica son una constante en todo el periodo romano. Las crustae aparecen en la parte occidental del mundo romano en las pinturas pompeyanas decorando zócalos (ABAD CASAL 1977-1978: 190) y desde ahí perdura en el tiempo hasta el Bajo Imperio cuando se convierte en el principal motivo, pasando inclusive a épocas medievales (ABAD CASAL 1977-1978: 189). Son, por tanto, un elemento consustancial a la pintura romana.

En Hispania, ciñéndonos a la decoración de balnea, existen ejemplos de crustae en la sudatio de Balazote (FERNÁNDEZ DÍAZ 2002-2003: 138-139), en la sala calefactada de La Isla de la Moral, en la parte inferior de la sala meridional del balneum de La Olmeda, en Requejo, en El Saucedo (GARCÍA ENTERO 2005: 847- 849), en Almedinilla, con diferentes tipos de imitaciones marmóreas incluido el brocatel, (HIDALGO PRIETO 1990: 116) y también en la villa de las Murias de Beloño (ABAD CASAL 1982 a: 35). Son innumerables las decoraciones de este tipo constatadas en otros puntos del Imperio, desde Oriente a Occidente. En Münsingen (KAPOSSY 1966, 38) se documentan crustae junto con los motivos marinos al igual que en Cambre. En Holstein ocupan el zócalo (DRACK 1988: fig. 43) y son similares al tipo c de Cambre (Fig. 5)

A la vista de las evidencias de las que disponemos no es factible una restitución hipotética de las crustae en el conjunto total. Se han de tener en cuenta una serie de datos: normalmente se adscriben a los zócalos aunque el brocatel ocupa en ocasiones las partes medias de la pared, al igual que el jaspeado (ABAD CASAL 1982 a: 298). De ahí que, aunque suponemos que en Cambre las crustae decoraron los zócalos, no se puede descartar que ocupasen las zonas medias. 
El motivo arquitectónico (Fig. 5 motivo e) es sin duda lo más original de todo el conjunto. Lo recuperado inicialmente conforma dos arquerías interpretadas en su momento como una puerta con significado simbólico (NAVEIRO LÓPEZ et al. 2008: 17). A raíz de los últimos hallazgos mencionados, hemos podido comprobar que los fragmentos en los que se representa este motivo aumentan sustancialmente, lo que nos lleva a pensar que la arquería continúa, dibujando un puente. Un paralelo con este motivo estaría en una pintura del siglo I d.C. perteneciente a la villa de Boscoreale, cercana a Pompeya, que se encuentra en la actualidad en el Bristish Museum (GR 1899.2-15.2 Paintings 19). En relación con las arcadas existe un paralelo en un mosaico de la Vega Baja, en Toledo, en el que se representan motivos marinos junto con diferentes edificios y una arquería que da acceso a un faro o una torre de vigilancia (NEIRA JIMÉNEZ 1997: 243).

Por otro lado, observamos que en los mosaicos que incorporan ciudades marítimas los edificios se representan con los sillares de piedra bien dibujados en perfecto aparejo isódomo, de igual modo que en el motivo arquitectónico de Cambre. Como ejemplos, diferentes mosaicos de Ostia, mosaico de Terme di Faro, de la statio $\mathrm{n}^{\mathrm{o}} 10 \mathrm{y}$ de la statio nº 46 (BLAZQUEZ MARTÍNEZ y GARCÍA-GELABERT 1990-91: fig. 3, 5 y 6) en los que aparecen animales acuáticos y barcos junto a las estructuras arquitectónicas; el mosaico del Palazzo del Conservatori de Roma que evoca un faro y una arquería (NOGUERA CELDRÁN 1995-1996: lám. 21); de similares características el mosaico del Antiquarium Comunale (NEIRA JIMÉNEZ 1997: fig. 26); así mismo el mosaico de Apamea (NEIRA JIMÉNEZ 1997: fig 28) o en el mosaico del Triunfo de Venus en la Casa del asno de Cuicul (Djemila) (NOGUERA CELDRÁN 1995-1996: lám. 11).

También se utiliza este recurso en escultura y así se observa en el sarcófago de Phylokirius procedente de Ostia que representa una escena de un puerto con faro y una edificación con arquerías (NOGUERA CELDRÁN 1995-1996: lám. 19). Sería factible establecer una relación entre las pinturas murales de Cambre con un puerto próximo, quizá el cercano Portus Brigantium, a poca distancia de la villa.

Interpretamos el motivo como composición del friso, en un lugar en que sirve de nexo de unión entre el mundo marino de la bóveda y el terrestre de las paredes, cumpliendo similar función a la que desempeñan los motivos vegetales de las plantas acuáticas en la decoración de las termas del sureste de la Casa de Mitreo en Mérida, que representan la orilla del mar (ABAD CASAL 1982 a: 64-65).

En cuanto a la cenefa, está en relación con el motivo que deriva de las características gotas de agua típicas del siglo I d.C. y denominadas "cenefas caladas", constatadas en Bilbilis (GUIRAL PELEGRÍN y MARTÍN BUENO 1996: 100). Documentado también este motivo en la villa de Requejo, en Santa Cristina de la Polvorosa (REGUERAS GRANDE 1990: 707).

A partir de los materiales recuperados en la excavación se establece una cronología que va de la segunda mitad del IV d.C. hasta finales del V d.C. En este abanico hay que situar las pinturas del balneum. Pueden formar parte de la decoración de la villa desde un primer momento o tratarse de una remodelación posterior.

Los mosaicos de similar temática, tan característicos en Galicia, concuerdan con esta cronología (BALIL ILLANA 1975: 262). 
Los motivos marinos tienen una larga tradición en Hispania y son muy utilizados en los complejos termales. Presentan un desarrollo a lo largo del tiempo: en el siglo I d.C. aparecen especies sueltas y escasas en número en relación con la superficie a decorar; en el siglo II d.C. se utilizan como relleno de paisajes y mitologías de fondo marino, en bóvedas y paredes; alcanzan su apogeo entre finales del siglo II d.C. y la primera mitad del III d.C. momento en que va desapareciendo como motivo ornamental y es sustituido por motivos geométricos (ABAD CASAL 1982 a). Sin embargo, no deja de utilizarse hasta el final del periodo romano.

En general, es un tipo decorativo muy extendido en provincias (GUIRAL PELEGRÍN 2000 a: 116). Una temática que fue muy bien aceptada por el gusto de los galaicorromanos, de ello son ejemplo los mosaicos marinos de Panxón, A Cigarrosa, Batitales en Lugo, Parada de Outeiro y Seminario de Santiago en Braga, además de las referencias de mosaicos de este mismo tipo en Cirro, Campo das Carvalheiras en Braga y Canelas en Poiares da Regua, también en Portugal (ACUÑA CASTROVIEJO 1973 a, b y 1974).

A la vista de los datos, la pintura del balneum de Cambre, un establecimiento de los siglos IV-V, está inmersa en los modelos habituales seguidos en el mundo romano, con las características propias de un establecimiento del ámbito provincial, en perfecta relación con otras villae de su contexto y muy en particular con los gustos galaicos por los temas marinos en decoración.

\section{Bibliografía}

ABAD CASAL, L. 1977-1978. "Las imitaciones de crustae en la pintura mural romana en España", Archivo Español de Arqueología, vol. 50-51, nº 135-138, pp. 189-208.

ABAD CASAL, L. 1982a. La pintura romana en España. Universidad de Alicante y Universidad de Sevilla, vol. I y II.

ABAD CASAL, L. 1982b. "Aspectos técnicos de la pintura mural romana”. Lucentum, Anales de la Universidad de Alicante, $\mathrm{n}^{0}$ 1, pp. 135-171.

ABAD CASAL, L. 1982c. "Algunas consideraciones sobre los colores romanos y su empleo en la pintura”, Homenaje a Sáez de Buruaga, pp. 397-406.

ACUÑA CASTROVIEJO, F. 1973a. "Notas introductorias para el estudio de los mosaicos romanos de Galicia” en XII CAN Jaen 1971, Zaragoza, pp. 709-718.

ACUÑA CASTROVIEJO, F. 1973b. Mosaicos romanos de Hispania Citerior. II. Conventus Lucensis. Studia Archaeologica. Santiago de Compostela/Valladolid, $\mathrm{n}^{0} 24$.

ACUÑA CASTROVIEJO, F. 1974. Mosaicos romanos de Hispania Citerior.III Conventus Bracarensis. Studia Archaeologica. Santiago de Compostela/Valladolid, ${ }^{0} 3$.

ACUÑA CASTROVIEJO, F. 1997. "Os mosaicos das ciudades e das villae", en Galicia castrexa e romana, Xunta de Galicia, pp. 211- 214.

ACUÑA CASTROVIEJO, F. 2013. "De novo sobre o Mosaico de Panxón e outras novas sobre a Musivaria na Gallaecia”, Revista Facultade de Letras, Ciências e Técnicas do Património, Universidade do Porto, vol. XII, pp. 143-157.

BALIL ILLANA, A. 1975. "Sobre los mosaicos romanos de Galicia: identificación de un taller musivario". Coloquios de la Association Internationale sur l'etude de le mosaique Antique II. Paris, pp. 259-263. 
BARBET, A. 2008. La peinture mural en la Gaule romaine. Paris, Picard.

BLÁZQUEZ MARTÍNEZ, J.M. y GARCÍA-GELABERT PÉREZ, M.P. 1990-91. “El transporte marítimo según las representaciones de los mosaicos romanos, relieves y pintura de Ostia”, Lucentum, IX-X, pp. 111- 121.

CASTILLO, A. del 1987. Inventario de la riqueza monumental y artística de Galicia. Fundación Pedro Barrie de la Maza, A Coruña.

DRACK, W. 1988. Pintura parietal romana dalla Svizzera. Raggi-Feldmeilen.

FERNÁNDEZ CASTRO, M.C. 1982. Villas romana en España. Ministerio de Cultura, Madrid.

FERNÁNDEZ DÍAZ, A. 2002-2003. "Pintura mural de la villa romana de Bazalote (Albacete)", Lucentum, XXI-XXII, pp. 135-161.

GARCÍA- ENTERO, V. 2005. Los balnea domésticos -ámbito rural y urbano- en la Hispania romana. Anejos de AEspA, XXXVII.

GARCÍA ENTERO, V. 2005-2006. "Las transformaciones de los balnea rurales domésticos”, CuPAUAM, 31-32, pp. 61-82.

GARCÍA ENTERO, V. y ARRIBAS DOMINGUEZ, R. 2000. "Los balnea de las villae y su proceso de monumentalización”, en FERNÁNDEZ OCHOA, C. y GARCÍA ENTERO, V. (eds.): Termas romanas en el Occidente del Imperio. II Coloquio Internacional de Arqueología de Gijón, 1999, pp. 83-96.

GONZÁLEZ SOUTELO, S. 2011. El valor del agua en el mundo antiguo. Fundación Pedro Barrié de la Maza, A Coruña.

GUIRAL PELEGRÍN, C. 1994. “Técnicas analíticas aplicadas a la pintura romana”. Revista A Distancia, $\mathrm{n}^{\mathrm{o}} 1$, pp. 43-50.

GUIRAL PELEGRÍN, C. 2000a. "Decoración pictórica de los edificios termales”, en FERNÁNDEZ OCHOA, C. y GARCÍA ENTERO, V. (eds.): Termas romanas en el Occidente del Imperio. II Coloquio Internacional de Arqueología en Gijón. 1999. pp. 115-121.

GUIRAL PELEGRÍN, C. 20oob. "La pintura romana en España: aportaciones recientes”, en NOGALES BASARRATE, T. (ed. lit.): La pintura antigua. Actas del Coloquio Internacional. Museo de Arte Romano, Mérida, 1996, pp. 21-36.

GUIRAL PELEGRÍN, C. y MARTÍN BUENO, M. 1996. Bilbilis I.Decoración pictórica y estucos ornamentales. Institución Fernando el católico, Zaragoza.

HIDALGO PRIETO, R. 1990. "Esquemas decorativos pictóricos de la villa romana de El Ruedo (Almedinilla, Córdoba)", Anales de arqueología cordobesa, $\mathrm{n}^{0} 1$, pp. 109-124.

KAPOSSY, B. (1966): Römische Wandmalereien aus Münsingen und Hölstein. Acta Bernensia, 4, Stämpfli, Bern.

MARTÍNEZ CORTIZAS, A. y VÁZQUEZ VARELA, J.M. 2002. "El clima en la Galicia romana: una aproximación interdisciplinar", Revista Real Academia Galega de Ciencias, no 20-21, pp. 87-104.

PÉREZ LOSADA, F. 2002. Entre a cidade e a aldea: estudo dos aglomerados secundarios romanos en Galicia. Brigantium 13, Museo Arqueolóxico e Histórico de San Antón, A Coruña.

NAVEIRO LÓPEZ, J. et al., 2008. O xacemento romano de Cambre: a escavación arqueolóxica, o traslado e a posta en valor. Concello de Cambre, Xunta de Galicia.

NEIRA JIMÉNEZ, M.L. 1997. “Sobre la representación de ciudades marítimas en mosaicos romanos”, Espacio, Tiempo y Forma. Serie II, Ha Antigua, no 10, pp. 219-151.

NOGUERA CELDRÁN, J.M. 1995-1996. "Instalaciones portuarias romanas: representaciones iconográficas y testimonio histórico”, AnMurcia, nºs 11-12, pp. 219-235.

REGUERAS GRANDE, F. 1990. "Restos de pinturas romanas en la provincia de Zamora”, Actas I Congreso Historia de Zamora, Zamora 1988, t.II, pp. 697-720.

REGUERAS GRANDE, F. 1992. "Las pinturas romanas del frigidarium de la villa de Requejo (Sta. Cristina de la Polvorosa, Zamora)”, en JIMÉNEZ SALVADOR, J.L.: I Coloquio de Pintura mural romana en España. Valencia,1989, pp. 115-122.

RIPOLL LÓPEZ, G. y ARCE MARTÍNEZ, J. 2001. "Transformación y final de las villae en Occidente (siglos IV-VIII): Problemas y perspectivas”, Arqueología y Territorio Medieval, nº 8, pp. 21-54. 


\section{Ediciones de las fuentes clásicas}

PLINIO: Naturalis Historia. Texte établi, traduit et commenté par Jacques André et al. Paris: Société d'edition "Les Belles Lettres", vol.XXXV

SENECA: Epistolas morales a Lucilio. Traducción y notas de Ismael Roca Meliá. Gredos, vol II.

VITRUBIO: Los diez libros de arquitectura. Introducción por Delfín Rodríguez Ruíz; versión española de José Luis Oliver Domingo. Alianza. 